\title{
Región y Nación. La construcción provincial de Chile. Siglo XIX
}

\author{
Armando Cartes Montory (Editor). Santiago de Chile: \\ Editorial Universitaria, 2020, 428 páginas
}

Silvina Sosa Vota*

La construcción de los Estados nacionales, como tema de interés de la historiografía, ha cobrado cada vez más importancia en las investigaciones sociales desde la década de 1980 . El escurridizo concepto moderno de "nación", según es definido por Hobsbawm (2018), ha estado en el centro del debate. Muchas de las discusiones sobre el tema se han concentrado en abordar las múltiples formas que esta abstracta idea ha tomado para convertirse en una realidad tangible para las personas que habitamos este mundo. Obras claves, como Comunidades imaginadas, de Benedict Anderson (1993), alentaron la reflexión sobre el tema en espacios extraeuropeos. No obstante, este tipo de producciones tambalearon a la hora de aplicar el análisis en la realidad latinoamericana y trabajos como el coordinado por François Xavier-Guerra y Antonio Annino (2008), entre otros, se preocuparon por pensar el problema desde un escenario diferente y con particularidades. En Chile, la inquietud también fue acogida, impulsada en parte por los festejos del bicentenario y por trabajos como el de Julio Pinto y Verónica Valdivia (2009), o el editado por Gabriel Cid y Alejandro San Francisco (2009), los cuales son referencia en esta materia, por nombrar solo algunos.

Esta brevísima lista sobre trabajos que estudian la construcción de la idea de "nación" sugiere que la dimensión territorial necesita ser

\footnotetext{
* Uruguaya. Licenciada en Historia y Magíster en Integración Contemporánea de América Latina, Universidade Federal da Integração Latino-Americana, Brasil. Candidata a doctora en Historia por la Universidad de Santiago de Chile. Becaria ANID Doctorado Nacional 2018, 21180162. E-mail: silvina.sosa.vota@gmail.com
} 
considerada. La "nación" no fue un molde aplicable a cualquier realidad. Lo escrito para Europa o Asia no es extrapolable al contexto latinoamericano, pues, pensando el problema desde este espacio, surgen matices y texturas que deben ser consideradas. Lo mismo es válido desde América Latina hacia Chile, donde, si bien existen grandes redes de relación, abordar el tema anclado desde un punto en específico del mapa brinda nuevas miradas y genera diferentes sentidos de observación.

El gran aporte del libro aquí reseñado, coordinado por Armando Cartes, es que introduce nuevos colores al estudio del tema de la nación decimonónica, pues nos invita a pensar a partir de otros espacios situados al margen de los tradicionales centros políticos desde los cuales se suele escribir la historia, la problemática de la construcción del Estado nacional y la aplicación del concepto de "nación", colocando como eje fundamental a la categoría de "región". En este sentido, el objetivo principal que la obra colectiva se propone es pensar Chile desde las regiones, como estrategia para construir nuevos sentidos sobre el tiempo pretérito. Esto partiendo del diagnóstico de que las perspectivas tradicionales de la historia de Chile, generalmente "santiagocéntricas", no hacen justicia a las múltiples realidades regionales de lo que hoy entendemos como componentes de un mismo Estado. La "idea de Chile" y como ésta tomó forma, no se vivenció ni modeló de la misma manera en Arica que en Chiloé, en Punta Arenas que en Talca.

Región y nación reúne el trabajo de varios investigadores en diversas etapas de desarrollo profesional a lo largo de doce capítulos, una introducción escrita por el coordinador de la obra y un prólogo de autoría de Marcela Ternavasio. Partiendo desde el norte de la actual conformación territorial de Chile y llegando al extremo sur en las últimas páginas, invita a un recorrido en el pasado, proponiéndose responder cómo cada uno de estos disímiles espacios llegó conformar parte de un mismo Estado a lo largo del siglo XIX.

Las delimitaciones territoriales sobre las cuales se trabaja en cada uno de los capítulos no se corresponden con la actual división política del Estado chileno, sino que se vinculan con regiones de dinámicas históricas y espaciales propias. Por sus diferentes lazos políticos, económicos, de comunicaciones y/o productivos, estas áreas pueden ser identificadas y pensadas como unidades de análisis territorial. 
En este sentido, los capítulos del libro consideran el "Norte Grande" (de autoría de Sergio González Miranda), Atacama (Joaquín Fernández y Dany Jerez), Coquimbo (Alex Ovalle), Valparaíso-Aconcagua (Eduardo Cavieres y Jaime Vito), Santiago ${ }^{1}$ (Valentina Verbal), Colchagua (Juan Cáceres), Talca (Carlos Zúñiga), Concepción (Armando Cartes), la Araucanía (Jorge Pinto), Valdivia-Osorno-Puerto Montt (Hernán Delgado), Chiloé (Tomás Catepillan) y Magallanes (Mateo Martinic).

Más allá de los distintos estilos y formatos de cada uno de los apartados, todos ellos toman un especial cuidado en abordar las tensiones derivadas del proceso de conformación de un Estado de Chile, y cómo fue proyectada o exigida una vinculación social, cultural y emocional al mismo en un periodo postindependentista. Se enfatizan constantemente las continuidades coloniales que fuera de Santiago de desarrollaban ya entrado el siglo XIX. Este aspecto no es menor, pues, acostumbrados a analizar la historia desde la capital, podemos caer en el desacierto de dar por sentada la Independencia y la idea de República en las décadas inmediatamente posteriores a las luchas contra los realistas españoles. La perspectiva regional evidencia discusiones, incertidumbres y negociaciones que diferentes territorios presentaron para incorporarse a la nueva unidad política emergente, además de matizar la idea de "independencia como ruptura", ya que se indican las estructuras coloniales como claves en la definición de aspectos económicos, políticos y sociales, llevando también a cuestionar las temporalidades tradicionales a partir de las cuales aprehendemos el pasado.

En este sentido, otra de las contribuciones del libro - especialmente dada por la forma en que se van hilvanando los diferentes capítuloses mostrar que el proceso de construcción nacional no es de ninguna forma homogéneo al interior del Estado chileno. Presenta diversas particularidades geográficas, históricas, políticas y económicas en las cuales se enraíza, y que es extremadamente necesario considerar. La heterogeneidad de lo que identificamos hoy como Chile se explicita en la obra coordinada por Cartes a través de las múltiples temporalidades y escenarios que presenta a lectores y lectoras.

1 Este capítulo destaca la importancia de también regionalizar el "centro". 
Por otro lado, si bien el punto de partida del libro es la actual delimitación política de Chile, acaba excediéndola y desnaturalizándola. Queda en evidencia la laxitud de las fronteras y su modelamiento a lo largo del tiempo en función de diferentes coyunturas, tanto al norte como al sur. Claramente, el "Norte Grande" y su "chilenización" se vinculan con procesos diferentes a los desarrollados en sur y su forma de incorporación al Estado, pero el conjunto de experiencias apunta a dejar clara una idea: el territorio se transforma, se construye, no está dado y no es natural. En ese mismo sentido, vinculando las regiones con espacios más allá del actual límite del Estado, puede observarse la pertenencia de Chile al entramado regional internacional en el cual está inserto, regionalizando al país y rompiendo así el aislacionismo y sentimiento de excepcionalidad en relación a los vecinos sudamericanos, idea presente en el imaginario de muchos chilenos y chilenas hasta nuestros días (Pizarro, 2003).

En suma, cómo toma forma la idea de "lo nacional", qué mecanismos fueron necesarios para introducir y hacer operativo el concepto en el siglo XIX, acaba siendo un problema que debe siempre abordarse desde una posición definida y explícita. El espacio desde el que se trabaje y sus relaciones, además de otras variables, brindan una subjetividad que emerge para ampliar la gama de matices que el problema merece. Por tanto, Región y nación invita a volver más protagonista esta variable territorial y subjetiva dentro de los análisis historiográficos.

La cartografía historiográfica de Chile en el siglo XIX, que propone el conjunto de trabajos que componen el libro, marca un camino que sin dudas debe ser ampliado, profundizado y abordado desde otras perspectivas teóricas, como la cultural y la social, que no adquieren mucho protagonismo en la selección de trabajos. Sin embargo, actúa como un importante llamado de atención y, ojalá, como punto de partida de curiosidad para continuar explorando desde la investigación del pasado las diferentes subjetividades que los posicionamientos exteriores a los centros de poder tradicionales nos permiten conocer. Asimismo, destaca poderosamente una nueva variable a considerar en los estudios sobre la construcción de los Estados nacionales decimonónicos: la regional.

Por esto último, el libro dirigido por Cartes puede ser considerado como una gran contribución intelectual, tanto para el espacio con el 
que dialoga inmediatamente, como para investigaciones al respecto de otros Estados nacionales distintos a Chile y a sus procesos de construcción y consolidación.

\section{Referencias bibliográficas}

Anderson, B. (1993). Comunidades imaginadas. Reflexiones sobre el origen y difusión del nacionalismo. México: Fondo de Cultura Económica.

Annino, A. y F. Guerra (coords.) (2008). Inventando la nación. Iberoamérica siglo XIX. México: Fondo de Cultura Económica.

Cid, G. y A. San Francisco (2009). Nación y nacionalismo en Chile. Siglo XIX. Vol. I. Santiago, Chile: Centro de Estudios Bicentenario.

Hobsbawm, E. (2018). Naciones y nacionalismo desde 1780. Santiago, Chile: Editorial Planeta.

Pinto, J. y V. Valdivia. (2009). ¿Chilenos todos? La construcción social de la nación (1810-1840). Santiago, Chile: LOM.

Pizarro, A. (2003). "Mitos y construcción del imaginario nacional cotidiano, en Atenea, № 487, pp. 103-111. 